\title{
Relevance of allosteric conformations and homocarnosine concentration on carnosinase activity
}

\author{
Verena Peters $\cdot$ Moustafa Kebbewar $\cdot$ Erwin W. Jansen $\cdot$ Cornelis Jakobs $\cdot$ Eva Riedl $\cdot$ \\ Hannes Koeppel • Dirk Frey • Katja Adelmann - Kristina Klingbeil • Matthias Mack • \\ Georg F. Hoffmann • Bart Janssen · Johannes Zschocke • Benito A. Yard
}

Received: 2 July 2009/ Accepted: 9 October 2009/Published online: 14 November 2009

(C) Springer-Verlag 2009

\begin{abstract}
Activity of carnosinase (CN1), the only dipeptidase with substrate specificity for carnosine or homocarnosine, varies greatly between individuals but increases clearly and significantly with age. Surprisingly, the lower $\mathrm{CN} 1$ activity in children is not reflected by differences in $\mathrm{CN} 1$ protein concentrations. $\mathrm{CN} 1$ is present in different allosteric conformations in children and adults since all sera obtained from children but not from adults were positive in ELISA and addition of DTT to the latter sera increased OD450 values. There was no quantitative difference in the amount of monomeric $\mathrm{CN} 1$ between children and adults. Further, CN1 activity was dose dependently inhibited by
\end{abstract}

V. Peters $(\bowtie) \cdot$ K. Klingbeil · G. F. Hoffmann

Division of Metabolic Diseases,

University Children's Hospital, Heidelberg, Germany

e-mail: verena.peters@med.uni-heidelberg.de

M. Kebbewar · B. Janssen · J. Zschocke

Institute of Human Genetics,

University Medical Centre Heidelberg,

Heidelberg, Germany

E. W. Jansen - C. Jakobs

Metabolic Unit, Department of Clinical Chemistry,

VU University Medical Centre, Amsterdam, The Netherlands

E. Riedl · H. Koeppel - D. Frey · K. Adelmann · B. A. Yard 5th Medical Clinic, University Medical Centre Mannheim, Medical Faculty Mannheim, Heidelberg University,

Heidelberg, Germany

M. Mack

Institute for Technical Microbiology, Mannheim University

of Applied Sciences, Mannheim, Germany

J. Zschocke

Divisions of Human Genetics and Clinical Genetics,

Medical University, Innsbruck, Austria homocarnosine. Addition of $80 \mu \mathrm{M}$ homocarnosine lowered $V_{\max }$ for carnosine from 440 to $356 \mathrm{pmol} / \mathrm{min} / \mu \mathrm{g}$ and increased $K_{\mathrm{m}}$ from 175 to $210 \mu \mathrm{M}$. The estimated $K_{\mathrm{i}}$ for homocarnosine was higher $(240 \mu \mathrm{M})$. Homocarnosine inhibits carnosine degradation and high homocarnosine concentrations in cerebrospinal fluid (CSF) may explain the lower carnosine degradation in CSF compared to serum. Because CN1 is implicated in the susceptibility for diabetic nephropathy (DN), our findings may have clinical implications for the treatment of diabetic patients with a high risk to develop DN. Homocarnosine treatment can be expected to reduce $\mathrm{CN} 1$ activity toward carnosine, resulting in higher carnosine levels.

Keywords Carnosine $\cdot$ Homocarnosine Carnosinase CN1 - Diabetic nephropathy

\section{Introduction}

Carnosine is a $\beta$-alanyl-L-histidine dipeptide found in high concentrations in the muscle but also in the central nervous system (for review see Crush 1970) from where it is released into the serum and cerebrospinal fluid. The role of carnosine is not completely understood (Bauer 2005; Quinn et al. 1992; Boldyrev and Severin 1990); it appears to function as an antioxidant and free radical scavenger (Baran 2000; Trombley et al. 2000; Boldyrev 1993, Boldyrev et al. 1993), can delay senescence of cultured fibroblasts (McFarland and Holliday 1994), may serve as an antiglycation agent (Hipkiss 1998) and has a positive effect on red blood cell deformability (Aydogan et al. 2008). In the central nervous system, carnosine meets many criteria for a neurotransmitter (Baslow 2009) modulating synaptic processes but also appears to be involved in neuroprotection 
(Tabakman et al. 2002). Treatment with carnosine significantly reduced infarct volume and improved neurological function in a mouse model of ischaemic stroke (Min et al. 2008). Treatment with 3 -alanine increased muscle carnosine concentrations (Kendrick et al. 2008; Baguet et al. 2009). Whereas there seems to be no positive effect of muscle carnosine loading on muscle strength (Kendrick et al. 2008), we can conclude from the data reported by Baguet et al. that carnosine is a stable compound in human skeletal muscle. A comparison of carnosine content between a group of elderly Korean males and young elite Korean swimmers showed no difference in muscle carnosine concentration (Kim 2009). Recently, we reported evidence that carnosine acts as a protective factor for the development of nephropathy in diabetes (Janssen et al. 2005). Carnosine is found in a low concentration (usually below $100 \mathrm{nM}$ ) in blood and cerebrospinal fluid (CSF). Homocarnosine ( $\gamma$-aminobutyric acid-L-histidine) also has a low concentration in blood (around $100 \mathrm{nM}$ ) but the concentration is much higher (up to $4 \mu \mathrm{M}$ ) in brain and CSF where it may act as a precursor for the neurotransmitter GABA (Perry et al. 1974). Homocarnosine concentration in the brain is about 100-fold higher than carnosine concentration (Gjessing et al. 1990) and its concentration in children's CSF is higher than in adults (Perry et al. 1968).

Two dipeptidases are known to cleave carnosine, denoted CN1 and CN2 (Teufel et al. 2003) and classified as members of the M20 metalloprotease family. CN2 functions as a cytosolic non-specific dipeptidase (EC 3.4.13.18) and is not present in serum or CSF. CN2 does not degrade homocarnosine and hydrolyzes carnosine only at alkaline pH (Teufel et al. 2003). CN1 represents human serum carnosinase (EC 3.4.13.20), the only dipeptidase with substrate specificity for carnosine or homocarnosine. The CN1 gene is expressed in the central nervous system of adults and to a lesser extent in liver (Teufel et al. 2003). The concentrations of CN1, carnosine and homocarnosine have been reported to vary greatly between individuals. Both enzyme and dipeptides are found only in small amounts in newborns (Lenney et al. 1982). CN1 activity increases with age; it is higher in females than males (Bando et al. 1984).

Reduced carnosinase activity (Willi et al. 1997) has been reported in patients with certain muscle disorders (Bando et al. 1990, Duane and Peters 1988) as well as in patients with Parkinson disease, multiple sclerosis or cerebrovascular accidents. In contrast, normal serum carnosinase activity was reported in patients with idiopathic epilepsy and motor neuron disease (Wassif et al. 1994). Recently, Balion et al. (2007) showed that patients with dementia had significant lower carnosinase activities in serum compared to controls. It remains unclear whether the reduced activities in some patients are disease-related or have an independent cause, for example reduced liver function.

Although serum carnosinase activity has been well characterized (Lenney et al. 1985; Pegova et al. 2000; Dunnett et al. 2002; Teufel et al. 2003) using carnosine as a substrate, homocarnosine metabolism and the differential effects of the two primary substrates on CN1 activity have not been studied in detail. Furthermore, little is known concerning the relationship between carnosine and homocarnosine concentrations and CN1 activity in CSF. Here we report that homocarnosine has a strong, competitive inhibitory effect on carnosine turnover mediated by CN1. Our results extend the understanding of brain carnosine and homocarnosine metabolism, as well as carnosine regulation in other tissues, and may have implications for the treatment of diabetic nephropathy.

\section{Materials and methods}

\section{Study cohort}

Blood samples were obtained from healthy controls for measuring $\mathrm{CN} 1$ activity and protein concentration as described above. Healthy controls consisted of 108 adults (range 19-62 years, 36 male and 72 female) and 52 infants and young children (range 6 days- 18 years). There was no significant age different between male and female individuals. All participants or their parents gave informed consent. Further, cerebrospinal fluid was obtained from anonymised spare material in 27 children in whom a lumbar puncture was performed in as a diagnostic measure but in whom other CSF tests showed normal results. The study was approved by the ethical committee (Second Ethics Committee of the Heidelberg University; amendment no. 2 and 3 to ethical approval no. 0193/2001).

\section{Dipeptide concentrations and CN1 activity}

Carnosine and homocarnosine concentrations were measured fluorometically by high-performance liquid chromatography as previously described by Jansen et al. (2006) and Schönherr (2002). CN1 activity was assayed according to a method described by Teufel et al. (2003). Briefly, the reaction was initiated by addition of carnosine and/or homocarnosine to serum or recombinant enzyme. The reaction was stopped after defined periods by adding $1 \%$ trichloracetic acid. Liberated histidine was derivatized by adding $o$-pthaldialdehyde (OPA) and fluorescence was read using a MicroTek plate reader $\left(\lambda_{\text {Exc }} 360 \mathrm{~nm}, \lambda_{\mathrm{Em}} 460 \mathrm{~nm}\right)$. Recombinant human CN1 was obtained from R\&D Systems (Minneapolis, USA). 


\section{CN1 ELISA}

To assess the amount of CN1 protein we developed a capture ELISA for the detection of human CN1. To this end, we raised monoclonal antibodies against recombinant human $\mathrm{CN} 1$. Balb/c mice were immunized with the recombinant protein and boosted after 2 and 4 weeks, respectively. Serum was collected to assess the antibody titre. Hereafter, the mice were sacrificed and splenocytes were fused with SP2/0 myeloma cells according to standard procedures. After fusion, the cells were plated at a density of 0.5 cells/well. Wells containing proliferating cells were tested for the presence of anti-carnosinase antibody by indirect immune fluorescence (IIF). Positive cultures were subsequently seeded at a density of 0.5 cells/ well and restested by IIF. Two stable anti-carnosinase clones, i.e. RKYS1 and RYSK173 (both IgG1), were selected for further analysis. The antibodies recognize an epitope in, or near, the dimerization domain of the $\mathrm{CN} 1$ protein.

A human CN1 ELISA was developed by coating high absorbant microtitre plates (Greiner BioChemia, Flacht, Germany) overnight with $100 \mu \mathrm{l}$ of goat polyclonal antihuman CN1 (10 $\mu \mathrm{g} / \mathrm{ml})$ (R\&D, Wiesbaden Germany). The plates were extensively washed and incubated with $5 \% \mathrm{~W} /$ $\mathrm{V}$ of dry milk powder to avoid nonspecific binding. For each sample and standard serial dilutions were carried out. The plates were placed on a shaker for $1 \mathrm{~h}$ and subsequently extensively washed with PBS/Tween. Hereafter purified anti-human carnosinase monoclonal $\operatorname{IgG}$ (clone RKYS1 or RYSK173, both gave identical results) was added for $1 \mathrm{~h}$ followed by extensively washing. Biotinylated goat anti-mouse $\operatorname{IgG}$ was added for $1 \mathrm{~h}$ followed by avidin-HRP. The plates were washed after each incubation. After addition of deep-blue peroxidase (POD) substrate (Roche diagnostics, Mannheim, Germany) the reaction was stopped after 15 min by addition of $50 \mu \mathrm{l}$ of $1 \mathrm{M} \mathrm{H}_{2} \mathrm{SO}_{4}$ and read in an ELISA reader at $450 \mathrm{~nm}$. CN1 protein concentrations were assessed in the linear part of the dilution curve. Sensitivity of the ELISA was approximately $20 \mathrm{ng} / \mathrm{ml}$.

\section{Western blot analysis}

Fifteen microliter of human serum was depleted for albumin and immunoglobulin using a commercially available kit (Ammersham, Freiburg, Germany). After depletion, the sample was approximately $40 \times$ diluted. Ten microliter of the diluted sample was denatured by boiling for $10 \mathrm{~min}$ in $\beta$-mercaptoethanol containing Laemmli sample buffer (Bio-Rad, München, Germany) prior to separation by $10 \%$ SDS-PAGE. In some experiments N-deglycosylation was performed by PNGase $\mathrm{F}$ treatment. Thereafter proteins were precipitated from the diluted sample by addition of 5 volumes of acetone and subsequently centrifuged for $10 \mathrm{~min}$ at $15.000 \mathrm{RPM}$. The pellet was dissolved in denaturation buffer (5\% SDS, $20 \mathrm{mM}$ Tris $\mathrm{pH} 7.5,0.4 \mathrm{M}$ DTT) and process as recommended by the manufacturer (New England Biolabs, Frankfurt, Germany). After electrophoresis proteins were transferred to a PVDF membrane (Roche, Mannheim, Germany) using semi-dry blotting. Membranes were blocked for $1 \mathrm{~h}$ at room temperature with $5 \%$ non-fat dry milk powder dissolved in Tris-buffered saline (TBS) containing 0.1\% Tween 20 (Sigma, Steinheim, Germany). The blots were incubated overnight at $4^{\circ} \mathrm{C}$ with a mouse monoclonal anti-CN1 antibody (Atlas Antibodies, Stockholm, Sweden). After washing with TBS/ Tween, the membranes were incubated with a horseradish peroxidase-conjugated secondary antibody (Santa Cruz Biotechnology, Heidelberg, Germany) for $1 \mathrm{~h}$ at room temperature. Immunoreactive bands were visualized using chemiluminescence (PerkinElmer, Boston, USA).

\section{Results}

Carnosine and homocarnosine degradation in serum and CSF

CN1 activity for carnosine as a substrate shows great variability but clearly increases with age for both serum (Fig. 1) and CSF (data not shown). CN1 activity was considerably higher in serum than in CSF (Table 1), and serum activities were non-significantly higher in females $(3.4 \pm 1.1 \mu \mathrm{mol} / \mathrm{ml} / \mathrm{h}, \quad n=62)$ than in males $(2.9 \pm$ $0.8 \mu \mathrm{mol} / \mathrm{ml} / \mathrm{h}, n=32$ ).

Homocarnosinase activity was below the detection limit in young children in both CSF and sera. For older controls, activities ranged from 0.12 to $0.14 \mu \mathrm{mol} / \mathrm{ml} / \mathrm{h}$ in serum and

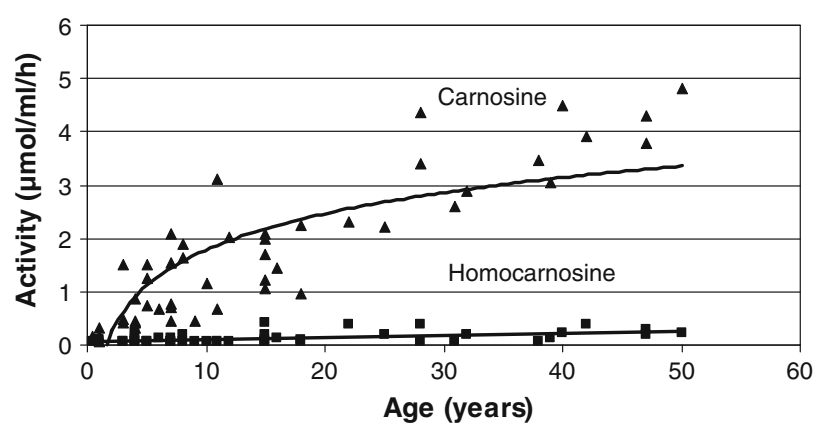

Fig. $1 \mathrm{CN} 1$ activity in serum comparing both substrates (carnosine and homocarnosine) in healthy controls. $\mathrm{CN} 1$ activity varies between individuals and increases with carnosine as substrate (triangle) as a function of age, whereas $\mathrm{CN} 1$ activity with homocarnosine as substrate (square) is generally lower and remains stable with increasing age 
Table 1 CN1 activity in serum and CSF for carnosine and homocarnosine as substrate

\begin{tabular}{lllllr}
\hline Material & $\begin{array}{l}\text { Age } \\
\text { (years) }\end{array}$ & $\begin{array}{l}\text { CN1 activity } \\
\text { with } \\
\text { carnosine as } \\
\text { substrate } \\
{[\mu \mathrm{mol} / \mathrm{ml} / \mathrm{h}]}\end{array}$ & $\begin{array}{l}N \\
\text { Serum }\end{array}$ & $\begin{array}{l}\text { CN1 activity with } \\
\text { homocarnosine } \\
\text { [s substrate }\end{array}$ & $n$ \\
& $0-1$ & $0.34 \pm 0.24$ & 10 & $<0.05$ & 5 \\
& $2-3$ & $0.63 \pm 0.4$ & 12 & $<0.05$ & 6 \\
& $4-10$ & $1.3 \pm 0.9$ & 30 & $0.12 \pm 0.06$ & 14 \\
& $11-20$ & $2.3 \pm 1.2$ & 20 & $0.14 \pm 0.09$ & 25 \\
& Above 20 & $3.2 \pm 0.9$ & 94 & $0.12 \pm 0.04$ & 16 \\
& $0-1$ & $0.07 \pm 0.006$ & 5 & $<0.05$ & 3 \\
& $2-3$ & $0.17 \pm 0.08$ & 10 & $0.08 \pm 0.02$ & 5 \\
& $4-10$ & $0.27 \pm 0.15$ & 14 & $0.09 \pm 0.05$ & 9 \\
& $11-20$ & $0.35 \pm 0.2$ & 10 & $0.07 \pm 0.03$ & 9 \\
& Above 20 & $0.8 \pm 0.22$ & 15 & $0.11 \pm 0.09$ & 11 \\
\hline
\end{tabular}

from 0.07 to $0.11 \mu \mathrm{mol} / \mathrm{ml} / \mathrm{h}$ in CSF. The increase of $\mathrm{CN} 1$ activity with age was much less pronounced for homocarnosine than for carnosine (Fig. 1), and activity for homocarnosine was not significantly different in serum and CSF (Table 1). Furthermore the gender difference was less pronounced for homocarnosine than for carnosine (females $=0.113 \pm 0.05$, males $=0.109 \pm 0.06$ ). Carnosine turnover increased with increasing carnosine concentrations, while increasing homocarnosine concentrations did not lead to a significant increase in homocarnosine turnover, suggesting that enzyme saturation is already achieved at homocarnosine concentrations of $40 \mu \mathrm{mol} / \mathrm{l}$.

Because CN1 activity for carnosine as substrate increased in an age-dependent fashion, we next assessed if the amount of $\mathrm{CN} 1$ protein was different in children and adults. In adults $\mathrm{CN} 1$ protein was almost undetectable in serum, while in EDTA-plasma significant amounts were detected. In contrast, $\mathrm{CN} 1$ protein was easily detected in both serum and EDTA plasma from children (Fig. 2). Although CN1 activity was significantly lower in children than in adults, similar amounts of $\mathrm{CN} 1$ protein were detected in EDTA plasma.

Since CN1 protein was always detected in plasma but, with the exception of one individual, not in serum of adults, our data might suggested that serum CN1 is present in different conformations. Accordingly, we added DTT to sera of adults to potentially stabilize CN1 and assessed if detection of CN1 by ELISA occurred under this condition. DTT dose-dependently increased OD450 values, suggesting that detection of $\mathrm{CN} 1$ in serum by ELISA depends on the conformation the protein (Fig. 3).

Inasmuch as the amount of $\mathrm{CN} 1$ protein in serum was significantly higher in children compared to adults and addition of DTT increased the detection of CN1 in ELISA,

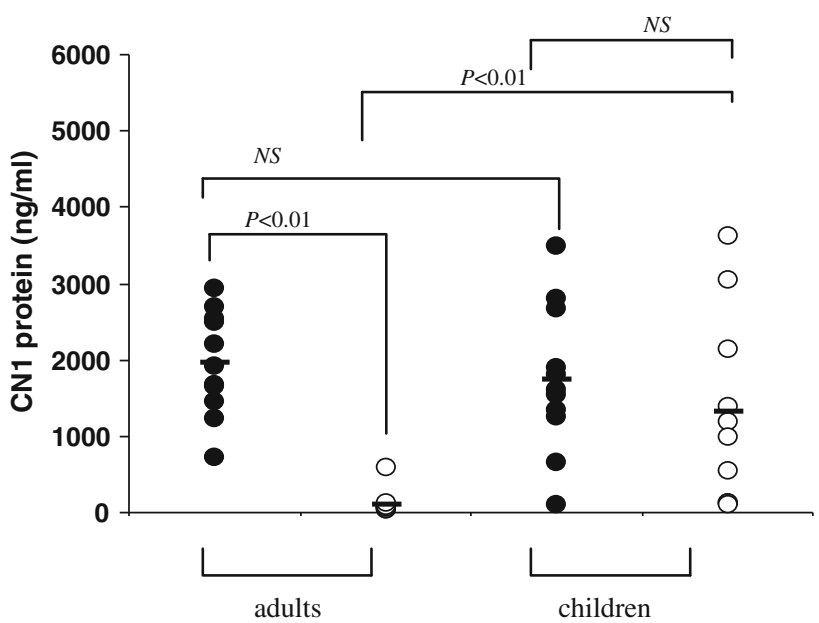

Fig. 2 CN1 was measured by ELISA in serial dilutions of serum (open circles) or EDTA plasma (closed circles) obtained from children $(n=11)$ and adults $(n=10)$ as described in materials and methods. CN1 concentrations were determined in the linear part of the dilution curve. The results of all individual samples are depicted; the mean of each group is depicted as a line. Statistical significance was determined by Student's $t$ test, a $P$ value $<0.05$ was considered as significant

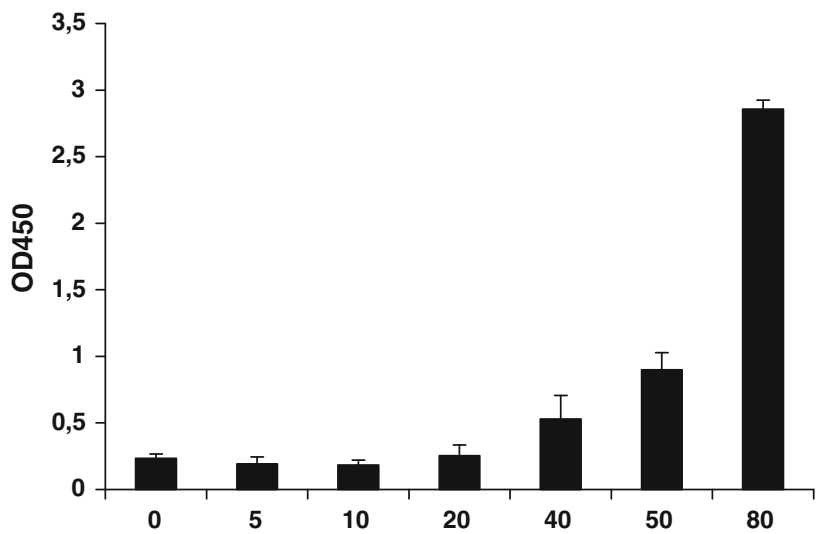

Fig. 3 Infuence of DTT on the detection of CN1 protein in serum of adults. Undiluted serum was added in the presence of different concentration of DTT to the ELISA plates. Thereafter, the ELISA was performed as described. The result of a representative serum obtained from an adult is depicted. At least three different sera were tested; they gave essentially the same results

we used Westernblot analysis to determine whether monomeric $\mathrm{CN} 1$ was more prevalent in children than adults. Under non-reducing conditions two immune-reactive bands with apparent molecular weight of approximately 150 and $65 \mathrm{kDa}$ were observed. The molecular weight of the latter band is in concordance with that of monomeric $\mathrm{CN} 1$. There was no consistent difference in the amount of monomeric $\mathrm{CN} 1$ in serum of adults and that of children. In two out of three children, a prominent $61 \mathrm{kDa}$ band was also detected, which was markedly less abundant 
in serum of adults (Fig. 4a). Under reducing conditions the upper band was shifted to approximately $130 \mathrm{kDa}$ while the $65 \mathrm{kDa}$ band did not change in molecular weight. Although addition of DTT clearly changed the conformation of $\mathrm{CN} 1$, as revealed by the change in mobility during electrophoreses, CN1 was not completely reduced by DTT to the monomeric form. To assess if the $150 \mathrm{kDa}$ band was a differentially $\mathrm{N}$-glycosylated $\mathrm{CN} 1$ isoform, the samples were treated with PNGase. The $150 \mathrm{kDa}$ band was partially resistant to PNGase as revealed by the appearance of a 120 and $130 \mathrm{kDa}$ band. The latter was likely due to the presence of DTT in the denaturation buffer which was required for PNGase treatment. The $65 \mathrm{kDa}$ band was shifted to $61 \mathrm{kDa}$ after PNGase treatment, suggesting that the $61 \mathrm{kDa}$ band present in serum of children is most likely a monomeric $\mathrm{CN} 1$ isoform completely or partially devoid of $\mathrm{N}$ glycosylation (Fig. 4b).

We next assessed in a different cohort of children if there was a difference in the amount of $\mathrm{CN} 1$ protein in serum, EDTA plasma and CSF within the same individual. We also assessed serum CN1 activity with carnosine as substrate in this cohort. In children below 1 year of age CN1 activity was not detectable. Consistent with this finding, CN1 protein was either not detectable by ELISA or was present in very small amounts when EDTA plasma was used. In general, the amount of $\mathrm{CN} 1$ protein was higher in EDTA plasma compared to serum. In CSF CN1 protein concentrations were lower than in serum. There was no clear correlation between $\mathrm{CN} 1$ activity and the amount of CN1, either when measured in EDTA plasma or when measured in serum (Table 2).

\section{Competition experiment with both substrates in serum}

To assess the ability of $\mathrm{CN} 1$ to utilize carnosine or homocarnosine, we measured $\mathrm{CN} 1$ activity with different combinations of carnosine and homocarnosine in serum samples obtained from healthy adults. The addition of increasing amounts of homocarnosine reduced $\mathrm{CN} 1$ activity with carnosine significantly in both serum (Fig. 5) and CSF (data not shown) compared to carnosine as sole substrate. The addition of $80 \mu \mathrm{mol} / \mathrm{l}$ homocarnosine decreased the carnosinase activity for carnosine from $2.6 \pm 0.15$ to $1.8 \pm 0.1 \mu \mathrm{mol} / \mathrm{ml} / \mathrm{h}$ significantly $(n=5 ; P<0.01$; Student's $t$ test) and $800 \mu \mathrm{mol} / \mathrm{l}$ homocarnosine decreased the activity to $0.6 \pm 0.09 \mu \mathrm{mol} / \mathrm{ml} / \mathrm{h} \quad(n=5 ; P<0.01$; Student's $t$ test) In contrast, another dipeptide (Leu-His) which is not degraded by carnosinase did not show any effect on CN1 activity (Fig. 5). Inhibition was immediate but reversible and enzyme activity recovered within 5-10 min. Hence, our results indicate that $\mathrm{CN} 1$ activity toward carnosine is inhibited by homocarnosine. Inhibition was dependent upon the amounts and ratio of both dipeptides in
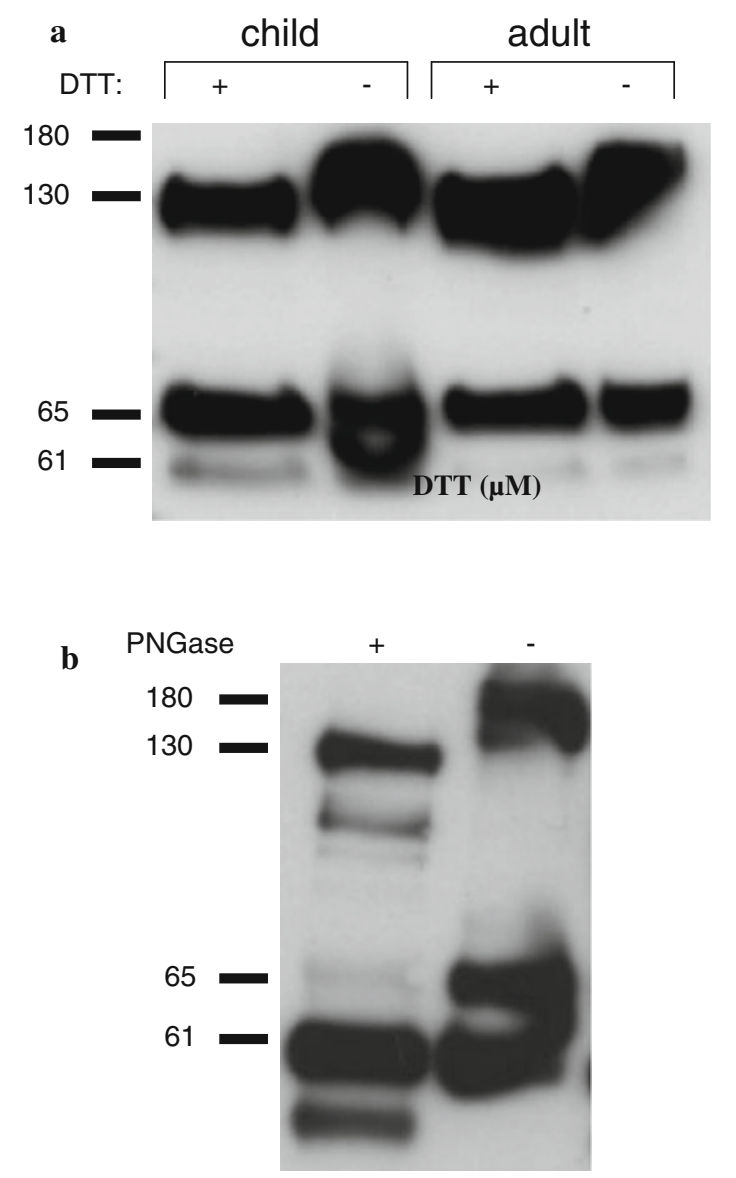

Fig. 4 Expression of $\mathrm{CN} 1$ in serum of adults and children. Albumin and IgG depleted serum was subjected to SDS-PAGE and Westernblotting. a The samples were either treated with DTT (reducing conditions) or were left untreated. Under reducing conditions two bands with apparent molecular weight of 130 and $65 \mathrm{kDa}$ respectively were detected. The latter band is in concordance to the molecular weight of monomeric CN1. Under non-reducing conditions immunoreactive band of approximately 150 and $65 \mathrm{kDa}$ were detected. Note the presence of an additional $61 \mathrm{kDa}$ band in serum of children. This was observed in two out of three children, while in adults $(n=3)$ this band was either not detected or weakly expressed. b Serum of a child was either treated with PNGase to remove N-glycosylation, or left untreated. SDS-PAGE was performed under non-reducing conditions for the untreated sample. Since DTT was present in denaturation buffer for PNGase, SDS-PAGE for the treated sample was performed under reducing conditions. The $150 \mathrm{kDa}$ band was partly resistant to PNGase as demonstrated by the appearance of a $120 \mathrm{kDa}$ band. The $130 \mathrm{kDa}$ band occurred due to the presence of DTT in the denaturation buffer. The $65 \mathrm{kDa}$ band was shifted to $61 \mathrm{kDa}$, corresponding to the lower band in the untreated serum. The lower band in the treated sample may represent a completely N-deglycosylated $\mathrm{CN} 1$ monomer or degradation product. The result of a representative blot $(n=3)$ is depicted in $\mathbf{a}, \mathbf{b}$

serum (Table 3). For all samples, carnosine turnover at a substrate concentration of $160 \mu \mathrm{M}$ carnosine was between 1.3 and $1.8 \mu \mathrm{mol} / \mathrm{ml} / \mathrm{h}$ and addition of homocarnosine lowered the degradation significantly $(P<0.01$, Student's $t$ test). Activity decreased to $0.8-1.2 \mu \mathrm{mol} / \mathrm{ml} / \mathrm{h}$ when homocarnosine concentration was added $(320 \mu \mathrm{M})$, and to 
Table 2 Serum CN1 activity and protein concentration in serum, EDTA plasma and CSF of children

Age is provided in years as otherwise stated in months or days

${ }^{\mathrm{b}} \mathrm{CN} 1$ activity was measured three times and is expressed in $\mu \mathrm{mol} / \mathrm{ml} / \mathrm{h}$

${ }^{c} \mathrm{CN} 1$ concentrations are expressed as $\mathrm{ng} / \mathrm{ml}$

\begin{tabular}{|c|c|c|c|c|}
\hline $\mathrm{Age}^{\mathrm{a}}$ & CN1 activity ${ }^{\mathrm{b}}$ & $\begin{array}{l}\text { CN1 protein } \\
\text { Plasma }^{\mathrm{c}}\end{array}$ & $\begin{array}{l}\text { CN1 protein } \\
\text { Serum }^{c}\end{array}$ & $\begin{array}{l}\text { CN1 protein } \\
\text { CSF }^{c}\end{array}$ \\
\hline 6 days & 0 & Not detectable & Not detectable & Not detectable \\
\hline 2 months & 0 & 24 & Not detectable & Not detectable \\
\hline 6 months & 0 & $34 \pm 5$ & Not detectable & Not detectable \\
\hline 9 & $0.3 \pm 0.04$ & $15,018 \pm 1,852$ & $788 \pm 392$ & $262 \pm 35$ \\
\hline 1 & $0.01 \pm 0.001$ & $199 \pm 21$ & Not detectable & Not detectable \\
\hline 1.5 & $0.1 \pm 0.02$ & $170 \pm 78$ & $39 \pm 1$ & $50 \pm 14$ \\
\hline 2 & $0.1 \pm 0.02$ & $107 \pm 12$ & $90 \pm 20$ & $42 \pm 23$ \\
\hline 4 & $2.6 \pm 0.2$ & $520 \pm 277$ & $304 \pm 84$ & $37 \pm 18$ \\
\hline 6 & $1.8 \pm 0.2$ & $2,384 \pm 821$ & $1,617 \pm 721$ & $190 \pm 11$ \\
\hline 9 & $0.4 \pm 0.05$ & $2,216 \pm 647$ & $1,704 \pm 856$ & $288 \pm 7$ \\
\hline 12 & $2.2 \pm 0.2$ & $1,307 \pm 551$ & $450 \pm 20$ & 28 \\
\hline 13 & $1.4 \pm 0.1$ & $11,650 \pm 403$ & $7,980 \pm 2,458$ & $181 \pm 48$ \\
\hline
\end{tabular}

$0.4-0.8 \mu \mathrm{mol} / \mathrm{ml} / \mathrm{h}$ with homocarnosine concentrations of $800 \mu \mathrm{M}$. Similar results were obtained for lower carnosine concentrations (data not shown).

We analyzed homocarnosine and carnosine degradation and histidine formation in samples with either carnosine as sole substrate or with both homocarnosine and carnosine together. When both substrates were available, both were degraded simultaneously (Fig. 6), but carnosine degradation and histidine formation were reduced in the presence of homocarnosine. We tested this effect for carnosine concentrations of 40,80,160, 320 and $960 \mu \mathrm{M}$ in combination with homocarnosine concentrations of 160,80 and $0 \mu \mathrm{M}$. Independent of the ratio of carnosine to homocarnosine, we observed significantly lower CN1 activities ( $P<0.01$; Student's $t$ test.) in the presence of homocarnosine (data not shown), even when carnosine concentration was 12 -fold higher than homocarnosine concentration.

\section{Activity of recombinant human CN1}

To confirm that carnosine and homocarnosine turnover in serum reflected $\mathrm{CN} 1$ activity and that no other serum component influenced the enzymatic reaction, we repeated the results with the recombinant human $\mathrm{CN} 1$. Without homocarnosine the apparent $K_{\mathrm{m}}$ for the conversion of carnosine to B-alanine and L-histidine was $175 \mu \mathrm{M}$ carnosine and $V_{\max }$ about $440 \mathrm{pmol} / \mathrm{min} / \mu \mathrm{g}$. The addition of $80 \mu \mathrm{M}$ homocarnosine lowered $V_{\max }$ to $356 \mathrm{pmol} / \mathrm{min} / \mu \mathrm{g}$ and increased $K_{\mathrm{m}}$ to a concentration of $210 \mu \mathrm{M}$ carnosine. Enzyme activity in the presence of $160 \mu \mathrm{M}$ carnosine and $80 \mu \mathrm{M}$ homocarnosine was $264 \mathrm{pmol} / \mathrm{min} / \mu \mathrm{g} \quad( \pm 22.4$; $n=5$ ) whilst increasing homocarnosine to $160 \mu \mathrm{M}$ lowered the maximal activity significantly $(P<0.01$; Student's $t$ test $)$ to $122 \mathrm{pmol} / \mathrm{min} / \mu \mathrm{g}( \pm 16.2 ; n=5)$. An activity of $40 \mathrm{pmol} / \mathrm{min} / \mu \mathrm{g}( \pm 5.3 ; n=5)$ was observed when homocarnosine was present in a concentration of $480 \mu \mathrm{M}$. The estimated $K_{\mathrm{i}}$ for homocarnosine was $240 \mu \mathrm{M}$ which shows a reduced affinity of CN1 toward carnosine in the presence of homocarnosine.

Carnosine turnover and homocarnosine concentrations in vivo

The correlation between carnosine turnover and homocarnosine concentrations in serum of control individuals is depicted in Fig. 7. Higher homocarnosine concentrations were associated with lower CN1 activity, in line with an inhibitory effect of homocarnosine on $\mathrm{CN} 1$ activity.
Fig. 5 CN1 activity with carnosine and an additional dipeptide. Carnosine degradation in serum can be lowered by the addition of homocarnosine (striped) whereas the addition of another dipeptide Leu-His (gray) has no effect on carnosine degradation $(n=5)$. With increasing amount of homocarnosine, $\mathrm{CN} 1$ activity for carnosine degradation decreases

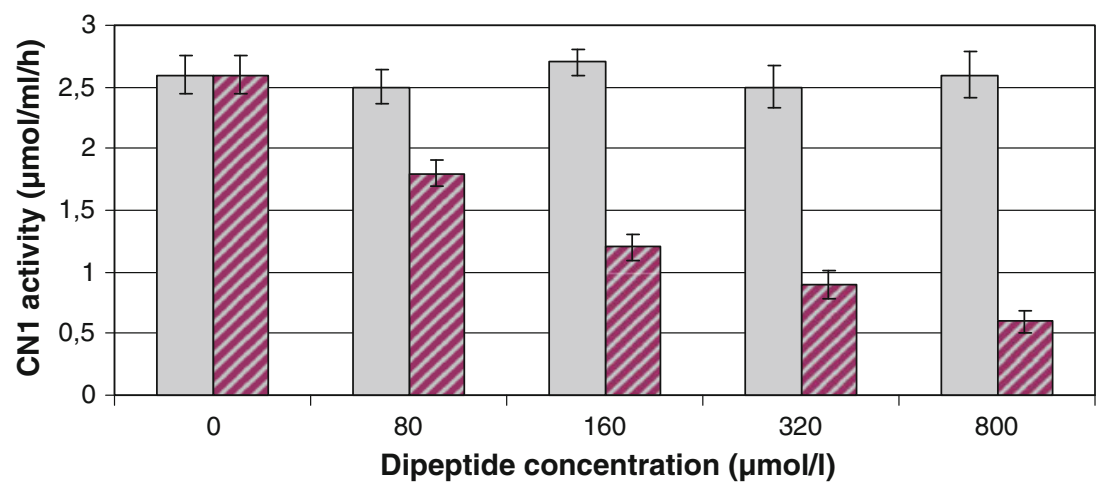


Table 3 CN1 activity in serum with a substrate combination of carnosine and homocarnosine

\begin{tabular}{|c|c|c|c|c|c|c|c|}
\hline \multirow[t]{2}{*}{ Ratio carnosine-homocarnosine } & \multicolumn{2}{|c|}{ Substrate concentration } & \multicolumn{5}{|c|}{ Activity $[\mu \mathrm{mol} / \mathrm{ml} / \mathrm{h}]$} \\
\hline & Carnosine $(\mu \mathrm{M})$ & Homocarnosine $(\mu \mathrm{M})$ & Control 1 & Control 2 & Control 3 & Control 4 & Average \\
\hline & 80 & - & $1.2 \pm 0.1$ & $0.9 \pm 0.11$ & $1.2 \pm 0.1$ & $1.3 \pm 0.12$ & 1.2 \\
\hline & 160 & - & $1.8 \pm 0.12$ & $1.8 \pm 0.14$ & $1.5 \pm 0.14$ & $1.3 \pm 0.4$ & 1.6 \\
\hline & 480 & - & $2.6 \pm 0.1$ & $2.8 \pm 0.12$ & $2.1 \pm 0.2$ & $3.1 \pm 0.25$ & 2.7 \\
\hline $1: 2$ & 160 & 320 & $0.9 \pm 0.01$ & $1.2 \pm 0.1$ & $1.1 \pm 0.26$ & $0.8 \pm 0.1$ & 1.0 \\
\hline $1: 2$ & 80 & 160 & $0.7 \pm 0.14$ & $0.7 \pm 0.1$ & $1.1 \pm 0.2$ & $0.9 \pm 0.17$ & 0.9 \\
\hline $1: 5$ & 160 & 800 & $0.7 \pm 0.12$ & $0.8 \pm 0.21$ & $0.4 \pm 0.06$ & $0.6 \pm 0.08$ & 0.6 \\
\hline $1: 5$ & 80 & 400 & $0.7 \pm 0.14$ & $0.7 \pm 0.2$ & $0.6 \pm 0.06$ & $0.6 \pm 0.1$ & 1.0 \\
\hline
\end{tabular}
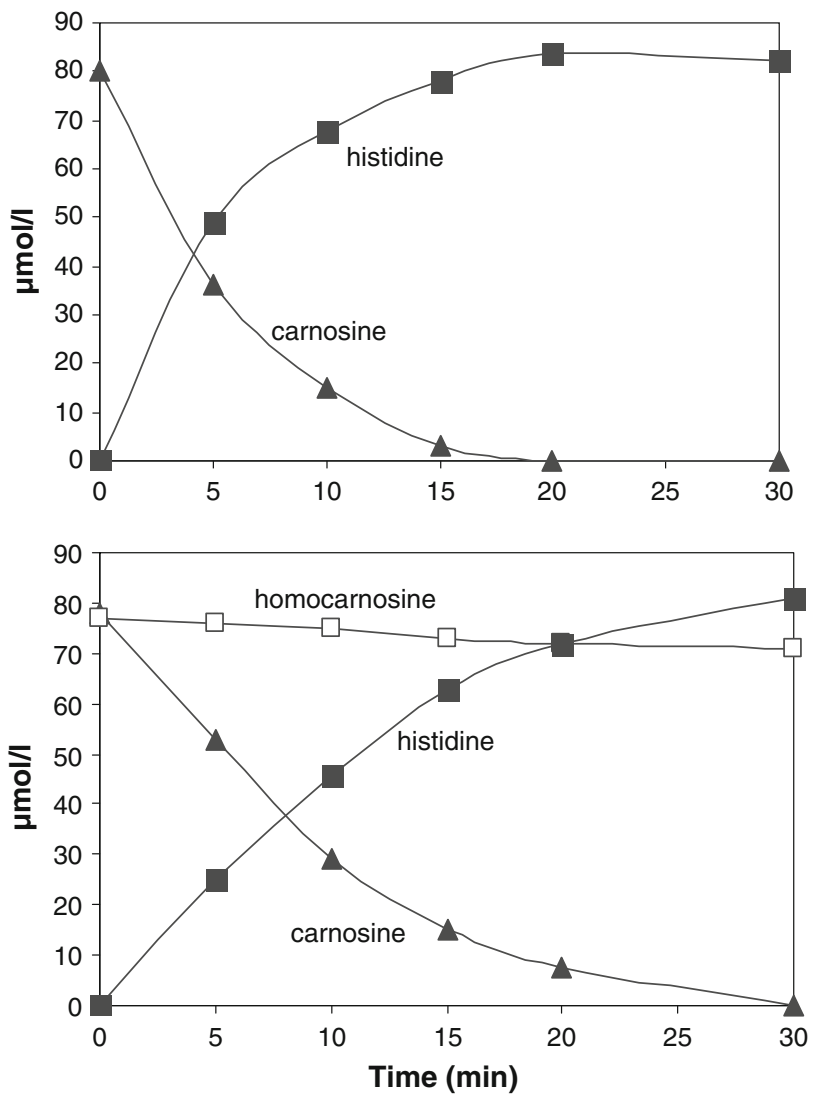

Fig. 6 Carnosine degradation (triangle) and histidine formation (square) with and without the addition of homocarnosine (open square). Carnosine degradation is slower in the addition of homocarnosine compared to carnosine as the only substrate

\section{Discussion}

In the present study we provide further data on $\mathrm{CN} 1$ activity and protein concentrations in serum and cerebrospinal fluid (CSF) of children and adults. The main findings of this study are the following. First, in children CN1 activity in serum is lower than adults but this is not reflected by differences in $\mathrm{CN} 1$ protein concentrations.

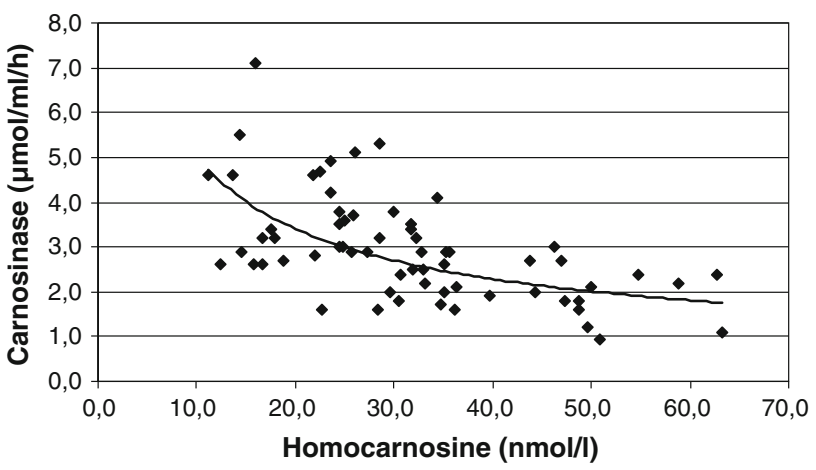

Fig. $7 \mathrm{CN} 1$ activity with carnosine as substrate in serum and homocarnosine concentration in plasma was measured in healthy adults. Carnosinase degradation is correlated with homocarnosine concentration

Second, CN1 is present in different allosteric conformations in children and adults. This is suggested by the observation that $\mathrm{CN} 1$ is always detected in sera of children by ELISA, while $90 \%$ of the adults were negative. In contrast, both children and adults were positive in CN1 ELISA when EDTA-plasma was used. Third, in all sera homocarnosine dose-dependently inhibited $\mathrm{CN} 1$ activity toward carnosine. The amount of homocarnosine in serum and CSF correlated inversely with CN1 activity.

Whereas CN1 activity for carnosine as substrate is well characterized (Teufel et al. 2003), little is known about its role in homocarnosine metabolism. $\mathrm{CN} 1$ is the only known enzyme with relevant activity toward both dipeptides, but the biological basis of the divergent concentrations of carnosine and homocarnosine in blood (low amounts of both dipeptides) and CNS (low amounts of carnosine but higher amounts of homocarnosine) has not been well characterized. Enzyme analyses carried out in the present study showed that homocarnosine turnover in blood is much lower than carnosine. CN1 activity in serum and CSF differ for carnosine and homocarnosine. In all age groups, $\mathrm{CN} 1$ activity for carnosine is four to six times higher in serum than in CSF, while this effect is not observed for 
homocarnosine as substrate. Although ELISA demonstrated higher amounts of CN1 protein in serum than in CSF, this does not sufficiently explain the biochemical patterns observed in vivo.

Importantly, our study demonstrates that $\mathrm{CN} 1$ seems to be present in a different allosteric conformation in children as compared to adults. Several arguments are in favor of this assumption. First, CN1 activity was significantly lower in children compared to adults, yet $\mathrm{CN} 1$ protein was seldomly detected in serum of the latter, while in all sera obtained from children $\mathrm{CN} 1$ protein was measured by ELISA. Because EDTA plasma of adults was always positive for $\mathrm{CN} 1$, we propose that in sera of adults the $\mathrm{CN} 1$ protein is either masked or not in the appropriate conformation for detection by ELISA. Second, addition of DTT to the sera significantly increased the OD450 values, suggesting that conformational changes of $\mathrm{CN} 1$ render the sera to become positive in ELISA.

It might be argued that addition of DTT confers CN1 dimers into monomers, and that the CN1 ELISA is preferentially measuring monomeric CN1. Differences between children and adults in the serum CN1 ELISA therefore could be due to differences in mono versus dimeric CN1. Westernblot analysis, however, demonstrated that there was no consistent difference in monomeric $\mathrm{CN} 1$ between sera from children and adults. We did, however, observe the presence of a monomeric $\mathrm{CN} 1$ isoform that is devoid of N-glycosylation. This isoform was abundantly present in two out of three sera from children but was weakly present or absent in sera from adults. It should also be emphasized that if the CN1 ELISA is only recognizing monomeric $\mathrm{CN} 1$, a positive ELISA in EDTA plasma would not be expected.

To our knowledge, this is the first report suggesting that in vivo $\mathrm{CN} 1$ is present in different allosteric conformations. Although our study does not provide a structural explanation for the different allosteric conformations, recently a study by Vistoli et al. (2006) has postulated that citrate ions can alter the conformation and activity of CN1. Given the fact that in the active center of $\mathrm{CN} 1$ different metal ions may be bound, it is conceivable that this might result in different allosteric conformations. Qualitative differences in, or the lack of, metal ion binding might explain a different $\mathrm{CN} 1$ conformation and low activity in children. The influence of metal ion binding, e.g. Mn or Cd, on CN1 activity has already been demonstrated (Lenney et al. 1982).

The results of the present study also indicate that dipeptide and dipeptidase patterns observed in blood and CSF are partially explained by a competitive inhibitory effect of homocarnosine on $\mathrm{CN} 1$. In control subjects there was a negative correlation between carnosine turnover and homocarnosine concentrations. Competition experiments in serum and with recombinant human $\mathrm{CN} 1$ showed that the presence of homocarnosine reduced $\mathrm{CN} 1$ activity for carnosine even at low homocarnosine concentrations whereas $\mathrm{CN} 1$ activity was unaffected by the addition of histidine or Leucine-Histidine (Leu-His) dipeptide. Hence, the correlation observed in controls was not explained by a cofactor or confounding variables. Rather, reduced carnosine degradation in the presence of homocarnosine is most likely due to competition of both substrates binding at the same active site of the CN1 enzyme. Since the turnover of homocarnosine is lower and carnosine cannot enter the active site while homocarnosine binds, the degradation of carnosine is also lowered. Even a 12-fold higher carnosine concentration compared to homocarnosine did not outcompete homocarnosine in binding to the enzyme. The inhibitory effect is reversible since after cleavage or removal of homocarnosine, carnosine metabolism is comparable to those samples in the absence of homocarnosine. Decreased carnosinase activity was not found for the dipeptide Leu-His showing that the inhibition is due only to homocarnosine. Our findings are consistent with those of Margolis et al. (1979) who demonstrated an inhibitory effect of homocarnosine on carnosinase.

The physiological role of carnosine is still uncertain. Carnosine is mainly found in skeletal muscle and the concentration is closely related to muscle activity. Carnosine presumably exerts antioxidative effects and we recently demonstrated that a leucine repeat polymorphism in the $\mathrm{CN} 1$ protein, affecting $\mathrm{CN} 1$ secretion across the cell membrane, is associated with susceptibility to developing diabetic nephropathy Janssen et al. (2005). Homocarnosine is thought to be a precursor for the neurotransmitter GABA, and this may explain the relatively high concentrations of homocarnosine in the brain and consequently the reduced dipeptidase activity toward carnosine.

In conclusion, homocarnosine appears to be an effective regulator of $\mathrm{CN} 1$ activity, and therefore its concentration might be an important metabolic parameter affecting the carnosine pathway. Moreover, a possible therapeutic option of homocarnosine for patients at risk for diabetic nephropathy has to be considered with caution. On the one hand, we would expect that homocarnosine treatment could reduce the serum degradation of carnosine. On the other hand, high concentrations of homocarnosine might lead to high concentrations of its degradation products $\gamma$-aminobutyric acid (GABA) and histidine. Histidine can be easily converted into histamine and the impact on autonomic nerve activity would be unpredictable and could result in further progression of renal insufficiency, since progressive renal disease has been shown to be associated with increased nerve activity.

However, the regulatory mechanisms of carnosine synthesis and degradation, its physiological role and a possible relevance of reduced activity require further investigation. 
Acknowledgments We thank Prof. K. Michael Gibson for comments and critical reading of the manuscript. Part of this study was supported by the EU-funded specific-target project PREDICTIONS on the identification of risk factors for the development of diabetic nephropathy as well as grants by the Deutsche Forschungsgemeinschaft to M. Mack and J Zschocke (Ma2510/3-1 and Zs17/5-1).

\section{References}

Aydogan S, Yapislar H, Artis S et al (2008) Impaired erythrocytes deformability in $\mathrm{H} 82) \mathrm{O}(2)$-induced oxidative stress: protective effect of L-carnosine. Clin Hemorheaol Microcirc 39:93-98

Baguet A, Reyngoudt H, Pottier A et al (2009) Carnosine loading and washout in human skeletal muscles. J Appl Physiol 106:837-842

Balion CM, Benson C, Raina PS et al (2007) Brain type carnosinase in dementia: a pilot study. BMC Neurol 7:38

Bando K, Shimotsuji T, Toyoshima H (1984) Fluorometric assay of human serum carnosinase activity in normal children, adults and patients with myopathy. Ann Clin Biochem 21:510-514

Baran EJ (2000) Metal complexes of carnosine. Biochemistry (Mosc) 65:757-765

Baslow MH (2009) A novel key-lock mechanism for inactivating amino acid neurotransmitters during transit across extracellular space. Amino Acids (epub ahead of print)

Bauer K (2005) Carnosine and homocarnosine, the forgotten, enigmatic peptides of the brain. Neurochem Res 30:1339-1345

Boldyrev AA (1993) Does carnosine possess direct antioxidant activity? Int J Biochem 25:1101-1107

Boldyrev AA, Severin SE (1990) The histidine-containing dipeptides, carnosine and anserine: distribution, properties and biological significance. Adv Enzyme Regul 30:175-194

Boldyrev AA, Koldobski A, Kurella E et al (1993) Natural histidinecontaining dipeptide carnosine as a potent hydrophilic antioxidant with membrane stabilizing function. A biomedical aspect. Mol Chem Neuropathol 19:185-192

Crush KG (1970) Carnosine and related substances in animal tissues. Comp Biochem Physiol 34:3-30

Duane P, Peters TJ (1988) Serum carnosinase activities in patients with alcoholic chronic skeletal muscle myopathy. Clin Sci (Lond) 75:185-190

Dunnett M, Harris RC, Dunnett CE et al (2002) Plasma carnosine concentration: diurnal variation and effects of age, exercise and muscle damage. Equine Vet J Suppl 34:283-287

Gjessing LR, Lunde HA, Morkid L et al (1990) Inborn errors of carnosine and homocarnosine metabolism. J Neural Transm Suppl 29:91-106

Hipkiss AR (1998) Carnosine, a protective, anti-ageing peptide? Int J Biochem Cell Biol 30:863-868

Jansen EW, Gibson KM, Shigematsu Y et al (2006) A novel, quantitative assay for homocarnosine in cerebrospinal fluid using stable-isotope dilution liquid chromatography-tandem mass spectrometry. J Chromatogr B Analyt Technol Biomed Life Sci 830:196-200

Janssen B, Hohenadel D, Brinkkoetter P et al (2005) Carnosine as a protective factor in diabetic nephropathy. Association with a leucine repeat of the carnosinase gene CNDP1. Diabetes $54: 2320-2327$
Kendrick IP, Harris RC, Kim HJ et al (2008) The effects of 10 weeks of resistance training combined with beta-alanine supplementation on whole body strength, force production, muscular endurance and body composition. Amino Acids 34:547-554

Kim HJ (2009) Comparison of the carnosine and taurine contents of vastus lateralis of elderly Korean males, with impaired glucose tolerance, and young elite Korean swimmers. Amino Acids 36:359-363

Lenney JF, Georg RP, Weiss AM et al (1982) Human serum carnosinase: characterization, distinction from cellular carnosinase, and actvitation by cadmium. Clin Chim Acta 123:221-231

Lenney JF, Peppers SC, Kucera-Orallo CM et al (1985) Characterization of human tissue carnosinsase. Biochem J 228:653-660

Margolis FL, Grillo M, Brown CE et al (1979) Enzymatic and immunological evidence for two forms of carnosinase in the mouse. Biochim Biophys Acta 570:311-323

McFarland GA, Holliday R (1994) Retardation of the senescence of cultured human diploid fibroblasts by carnosine. Exp Cell Res 212:167-175

Min J, Senut MC, Rajanikant K (2008) Differential neuroprotective effects of carnosine, anserine and $N$-acetyl carnosine against permanent focal ischemia. J Neurosci Res 86:2984-2991

Pegova A, Abe H, Boldyrev A (2000) Hydrolysis of carnosine and related compounds by mammalian carnosinases. Comp Biochem Physiol B Biochem Mol Biol 127:443-446

Perry TL, Hansen S, Stedman D et al (1968) Homocarnosine in human cerebrospinal fluid: an age-dependent phenomenon. J Neurochem 15:1203-1206

Perry TL, Hansen S, Kennedy J (1974) CSF amino acids and plasmaCSF amino acid ratios in adults. J Neurochem 24:587-589

Quinn PJ, Boldyrev AA, Formazuyk VE (1992) Carnosine: its properties, functions and potential therapeutic applications. Mol Aspects Med 13:379-444

Schönherr J (2002) Analysis of products of animal origin in feeds by determination of carnosine and related dipeptides by highperformance liquid chromatography. J Agric Food Chem 27:1945-1950

Tabakman R, Lazarovici P, Kohen R (2002) Neuroprotective effects of carnosine and homocarnosine on pheochromocytoma PC12 cells exposed to ischemia. J Neurosci Res 68:463-469

Teufel M, Saudek V, Ledig J-P et al (2003) Sequence identification and characterization of human carnosinase and a closely related non-specific dipeptidase. JBC 278:6521-6531

Trombley PQ, Horning MS, Blakemore LJ (2000) Interactions between carnosine and zinc and copper: implications for neuromodulation and neuroprotection. Biochemistry (Mosc) 65:807-816

Vistoli G, Pedretti A, Cattaneo M et al (2006) Homology modelling of human serum carnosinase, a potential medicinal target, and MD simulation of its allosteric activation by citrate. J Med Chem 49(11):3269-3277

Wassif WS, Sherwood RA, Amir A (1994) Serum carnosinase activities in central nervous system disorders. Clin Chim Acta 225:57-64

Willi SM, Zhang Y, Hill JB et al (1997) A deletion in the long arm of chromosome 18 in a child with serum carnosinase deficiency. Pediatr Res 41:210-213 